\title{
RISKY SEXUAL BEHAVIORS AND ASSOCIATED FACTORS AMONG MALE AND FEMALE STUDENTS IN JIMMA ZONE PREPARATORY SCHOOLS, SOUTH WEST ETHIOPIA: COMPARATIVE STUDY
}

\author{
Netsanet Fentahun $^{1 *}$, Abebe Mamo ${ }^{1}$
}

ABSTRACT

BACKGROUND: Youth engage in risk sexual behavior due to insufficient knowledge of reproductive health and family planning. Youth sexual behavior is important not only because of the possible reproductive outcomes, but also because of sexually transmitted infections. The level of risks and sexual behaviors are different between male and female youth due to sexual exposure and socio-cultural factors. The aim of this study was to compare risky sexual behaviors and associated factors among male and female preparatory school (grades 11 and 12) students in Jimma Zone.

METHODS: A comparative cross-sectional study was conducted in 5 randomly selected preparatory schools of Jimma Zone. A total of 520 students were selected using simple random sampling technique. A structured, pretested and self-administered questionnaire was used to collect data. Both descriptive analysis and binary logistic regressions were performed on the data to understand risky sexual behaviors among students.

RESULTS: Twenty-two (25.9\%) of male and 25(21.6\%) of female students had two or more sexual partners in the last six months. Eighty-three (32.3\%), 113(43.5\%) male and female students were sexually at risk in the last six months. Only $8(9.4 \%)$ of the male and $10(8.6 \%)$ of the female students used condom consistently in the last six months. Female students living away from their parents were 3 times more likely to be at risk than students living with their parents (OR 95\%CI 3.0(1.48-6.34)). Female students who consumed alcohol were 7 times more likely to be at risk than those who did not consume alcohol (OR 95\%CI 7.27(3.36-15.7)). Male students who consumed alcohol were 2.8 times more likely to be at risk than those who did not consumed alcohol (OR 95\%CI, 2.81(1.3-6.06)). Male students who chewed khat were 4.6 times more likely to be at risk than students who did not chew khat (OR 95\%CI, 4.58(1.95-10.76).

CONCLUSION: Living arrangement, educational status of parents, family connectedness, alcohol consumption and khat-chewing were the major predictors of risky sexual behavior. Therefore, School, family and zonal education office should be involved in reducing the risky sexual behavior of school youth.

KEYWORDS: Risk Sexual Behavior, Gender, School

DOI: http://dx.doi.org/10.4314/ejhs.v24i1.8

\section{INTRODUCTION}

One-fifth of the world's population includes youth and young adults, with more than four-fifths in developing countries. During the transition from childhood to adulthood, youth establish patterns of behavior and make lifestyle choices that affect both their current and future health $(1,2)$.
Sexual activities among youth have been reported to be on the increase worldwide. Most youth throughout the world engage in sexual intercourse by age 20, whether married or unmarried $(3,4)$. Youth are at high danger of risky sexual behaviors and reproductive health problems. But these problems are not considered health priorities by assuming young people have lower morbidity;

\footnotetext{
${ }^{1}$ Department of Health Education and Behavioral Sciences, Jimma University, Jimma, Ethiopia

*Corresponding Author: Netsanet Fentahun, P.O. Box 378, Email: netsanet_fentahun@yahoo.com
} 
mortality and good knowledge than older and adult age groups (5). Youth have limited access to reproductive health services and risky sexual behavior. Their reproductive health strategies demand a multi-sector and integrated approach on risky sexual factors and unsafe sexual behavior (6, 7).

Young age is a critical developmental period when many youth begin to define and clarify their sexual values and start to experiment with sexual behaviors. Most of these youth are students and they are also at a high risk for unsafe sexual behaviors and problems like HIV/AIDS or STI, unwanted pregnancy, abortion, poor school performance, high school dropout rate, psycho-social problems, conduct disorder, divorce, and economic problems $(8,9)$.

In the era of HIV/AIDS and reproductive health, it is crucial to understand the determinants of sexual activities among the youth in order to inform policies and programs that help protect them (10, 11). Sexual behavior and reproductive health of youth in developing countries have attracted a considerable attention over the last 15 years. But, a large proportion of the population in these countries is affected by HIV/AIDS and reproductive health problems. The sexual behavior of youth is important not only because of the possible reproductive outcomes but also because of the fact that risky sexual behavior is associated with sexually transmitted infections $(12,13)$.

According to the 2011 EDHS, 1.5\% of adults aged 15-49 years are infected with HIV. Among women aged 15-49 years, HIV prevalence is $1.9 \%$, and among men aged 15-49 years, HIV prevalence is $1.0 \%$. Among the age group of 15-24 years, HIV prevalence is $0.4 \%$ (14). The third baseline assessment of mobile HIV counseling and testing program in Oromiya Regional State showed that most-at-risk populations of Jimma Town were estimated about 55,879 of which $70.5 \%$ were inschool youth and college student (15).

In Jimma Town, $17.9 \%$ the high school of adolescents $(6.7 \%$ of females and $11.2 \%$ of males) were involved in unprotected sexual activities. In Addis Ababa City, about 25\% of the sexually active males were reported to have visited female commercial sex workers. Out of these, $36 \%$ reported that they had used condom $(16,17)$. But, these studies are not up-to-date. On the contrary, behavior is dynamic in nature. Therefore, this study gives the present image of risky sexual behavior and its associated factors in Jimma Zone. The study hypothesizes that there is a difference in risky sexual behavior and its associated factors among male and female preparatory school students in the zone in focus.

\section{METHODS AND MATERIALS}

Study Area and Period: A comparative crosssectional study was conducted in Jimma Zone from February 14-30/2012. Jimma Town is the capital of Jimma Zone and it is located $356 \mathrm{~km}$ from Addis Ababa in South West Ethiopia. In 2011/12, there were 985 governmental and private schools in Jimma Zone, and 9 preparatory schools during the study period. These schools provide educational services to 3065 students (male-1879 and females-1186). Of the nine preparatory schools (grades 11 and 12) of Jimma, seven are in Jimma Zone and two are located in Jimma Town (15).

Study population: Sample students whose ages ranged between 15-24 years were selected from five preparatory schools in Jimma Zone to participate in the study. The sample size was determined using two population proportions with the following assumption: the proportion of male in-school students who were sexually at risk $=57 \%$, the proportion of female in-school students who were sexually at risk $=48 \%$ (19) confidence interval $=$ $95 \%$, power $=80 \%$ and non-response $=10 \%$. The final sample size was 520 preparatory school students [260 male s and 260 females).

Sampling technique: Nine preparatory schools in Jimma Zone were identified and listed. Then five preparatory schools (grades 11 and 12) were selected from nine preparatory schools using simple random sampling. These students were selected based on their gender (male and female).Then, lottery method was employed to select the participants from each selected schools.

Measurements: A pretested, structured and translated questionnaire (Afan Oromo and Amharic) adapted from various sexually risky behavior studies was used to collect data (18-24). The measurements including socio-demographic characteristics, individual factors (yes/no and multiple choices items), family environment (family connectedness (10 items Likert scale with five scales), parental monitoring (2 yes/no items), parental communication (2 yes/no items) and family support (10 items Likert scale with five scales)), school attachment(teacherstudent relationship and school-student relationship (8 items with 4-point Likert scale)), peer pressure (5 items with 3-point Likert scale), community factors (6 items with 5-point Likert scale), risky sexual behavior(It sought information on whether the 
participants had engaged in sexual inter-course during the past 6 months, the number of sex partners during the past 6 months, condom use in their every instance of sexual inter-course).

Regarding number of sex partners, the responses were coded 0 if the participants never had sex, 1 if the number reported was 1 , and 2 if the number reported was 2 or more. Regarding condom use, the responses were coded 0 if the answer was "yes and 1 if the answer was "no." inconsistently condoms use and having two or more sexual partners in the last six months were considered as risky sexual behavior. Since family connectedness and family support were measured using Likert scale, family connectedness and family support scores were analyzed as a continuous variable by calculating the total score of the items.

Data collectors: Data were collected for 15 days by seven trained data collectors who had at least a diploma in clinical nursing. Five Master's of Public Health students participated in supervising the data collectors.

Data quality management and assurance: The questionnaire was translated into two local languages (Afan Oromo and Amharic) and back translated into English by another translator. Pre-testing of the questionnaire was undertaken in 5\% of the sample size in similar areas before the actual data collection. A three days' intensive training was offered to all supervisors and data collectors. The overall activity was monitored carefully by the supervisors and the principal investigator during data collection. The content validity of the questionnaire was assured by experts/statisticians who had experience on risky sexual behaviors. The internal consistency of the items of the questionnaire was greater than 0.7.

Data processing and analysis: Data were checked for completeness and consistency each day after collection. Data entry and analyses were performed using SPSS version 16 for Windows. Multicolinearity was checked by using Tolerance Statistics and Variance Inflation Factor. Tolerance statistic=the tolerance statistics is 1-R2 for this second regression. (R-square is the amount of variance in a dependent variable in a multiple regression explained by a combination of all of the independent variables). Tolerance statistics below 0.20 is generally considered cause for concern. Variance Inflation Factor=One divided by tolerance statistics. A Variance Inflation Factor of greater than 5 is generally considered evidence of Multicollinearity. For this study, $\mathrm{R}^{2}$ was 0.56 . From this evidence, the Tolerance statistics was 0.44 and the Variance Inflation Factor was 2.2. Based on this result, we ascertained that there was no Multicolinearity.

For interaction, we tried to see the association between genders with other independent variables. The result showed that gender was associated with chewing khat, watching pornographic films, religious involvement, living arrangements, residence, family connectedness, family support and school attachment. This indicates that there is an interaction between gender and chewing khat, watching pornographic films, religious involvement, living arrangements, residence, family connectedness, family support and school attachment. If there is an interaction, stratified analysis is recommended. Due to interaction effect, we stratified the analysis by gender. First, descriptive analysis was carried out to explore the socio-demographic characteristics of the respondents and other independent and the dependent variables. After Bivariate logistic regression analysis was performed, we carried out multiple logistic regression to identify the independent predictors of risky sexual behavior at $\mathrm{p}$-value $<0.05$.

Ethical Considerations: The study protocol was approved by the Ethical Clearance Committee of the College of Public Health and Medical Sciences, Jimma University. A permission letter was obtained from Jimma Zone Educational Office. An official letter of co-operation was written to the respective schools. The participants were informed about the purpose, procedures, potential risks and benefits of the study. Written informed consent was obtained from each participant. In order to protect confidentiality, names or school IDs were not included in the written questionnaire.

\section{RESULTS}

Socio-demographic characteristics: Out of 520 study participants, 517 students were interviewed resulting in a response rate of 99.4\% . Regarding sex, 260(50.3\%) were females and the mean age of the students was 18.6 (SD \pm 1.6) with a minimum of 15 years and maximum 24 of years. As regards the living arrangement, $156(60.7 \%)$ and $131(50.4 \%)$ of the male and the female students were respectively living away from their parents (Table 1). 
Table 1: Distribution of socio-demographic characteristics of students in Jimma Zone preparatory schools, February, 2012, N=517

\begin{tabular}{|c|c|c|}
\hline \multirow[b]{2}{*}{ Variables } & \multicolumn{2}{|c|}{ Sex } \\
\hline & $\begin{array}{c}\text { Male } \\
(\text { No }(\%))\end{array}$ & $\begin{array}{l}\text { Female } \\
(\text { No }(\%))\end{array}$ \\
\hline \multicolumn{3}{|l|}{ Grade level: } \\
\hline \multirow{2}{*}{$\begin{array}{l}11^{\text {th }} \text { grade } \\
12^{\text {th }} \text { grade }\end{array}$} & $83(32.3 \%)$ & $77(29.6 \%)$ \\
\hline & $174(67.7 \%)$ & $183(70.4 \%)$ \\
\hline \multicolumn{3}{|l|}{ Age } \\
\hline $15-19$ & $199(77.4 \%)$ & $200(76.9 \%)$ \\
\hline $20-24$ & $58(22.6 \%)$ & $60(23.1 \%)$ \\
\hline \multicolumn{3}{|l|}{ Living Arrangements } \\
\hline Living with parents & $101(39.3 \%)$ & $129(49.6 \%)$ \\
\hline Living away from parents & $156(60.7 \%)$ & $131(50.4 \%)$ \\
\hline \multicolumn{3}{|l|}{ Residence } \\
\hline Rural & $99(38.5 \%)$ & $127(48.8 \%)$ \\
\hline Urban & $158(61.5 \%)$ & $133(51.2 \%)$ \\
\hline \multicolumn{3}{|l|}{ Religion } \\
\hline Orthodox & $110(42.8 \%)$ & $129(49.6 \%)$ \\
\hline Muslim & $114(44.4 \%)$ & $71(27.3 \%)$ \\
\hline Protestant & $30(11.7 \%)$ & $56(21.5 \%)$ \\
\hline Catholic & $3(1.2 \%)$ & $4(1.5 \%)$ \\
\hline \multicolumn{3}{|l|}{ Educational status of mother } \\
\hline Illiterate & $79(30.7 \%)$ & $104(40.0 \%)$ \\
\hline Read and write & $98(38.1 \%)$ & $90(34.6 \%)$ \\
\hline Elementary & $29(11.3 \%)$ & $25(9.6 \%)$ \\
\hline Secondary and above & $51(19.8 \%)$ & $41(15.8 \%)$ \\
\hline \multicolumn{3}{|l|}{ Educational status of father } \\
\hline Illiterate & $64(24.9 \%)$ & $63(24.2 \%)$ \\
\hline Read and write & $67(26.1 \%)$ & $78(30.0 \%)$ \\
\hline Elementary & $49(19.1 \%)$ & $53(20.4 \%)$ \\
\hline Secondary and above & $77(30.0 \%)$ & $66(25.4 \%)$ \\
\hline \multicolumn{3}{|l|}{ Peer- Pressure } \\
\hline High & $79(30.7 \%)$ & $70(26.9 \%)$ \\
\hline Low & $178(69.3 \%)$ & $190(73.1 \%)$ \\
\hline \multicolumn{3}{|l|}{ Family Monitoring } \\
\hline Yes & $130(50.6 \%)$ & $110(42.3 \%)$ \\
\hline No & $127(49.4 \%)$ & $150(57.7 \%)$ \\
\hline
\end{tabular}

Individual factors and risky sexual behaviors: Respondents were asked if they had ever had sexual intercourse with an individual of the opposite sex, and 85(33.1\%), 116(44.6\%) male and female students said, respectively, that they had this practice. Regarding religious practice, 181(70.4\%), $157(60.4 \%)$ male and female students were not attending religious institutions respectively. Eighty seven $(33.9 \%)$ of the male and $72(27.7 \%)$ of the female students consumed alcohol and 115(44.7\%) of the male and 71(27.3\%) of the female students in the stated order watched pornographic movies in the last six months. One hundred and sixteen (45.1\%), $89(34.2 \%)$ of the male and female students were involved in chewing khat respectively. Twenty-two
$(25.9 \%)$ of the male and $25(21.6 \%)$ of the female students reported that they had two or more sexual partners in the last six months. Eightythree $(32.3 \%), 113(43.5 \%)$ male and female students were respectively sexually at risk in the last six months. Only $8(9.4 \%)$ of the male and $10(8.6 \%)$ of the female students respectively used condoms consistently in the last six months.

Family connectedness, family support, school attachment and community factors were analyzed as continuous variables. The mean scores of family connectedness for male and female students were 38.45(SD + 11.0), 36.57(SD + 12.7) respectively. The mean scores of family support for male and female students were $28.69(\mathrm{SD} \pm 5.8), 28.74(\mathrm{SD} \pm$ 
5.3) respectively. The mean score of school attachment for male and female students were $16.70(\mathrm{SD}+3.0), 16.62(\mathrm{SD}+3.0)$ respectively. The mean score of community factors for male and female students were 22.00( $\mathrm{SD} \pm$ 5.6), 21.38( $\mathrm{SD} \pm$ 5.1 ) in the stated order (Table 2).

Table 2: Frequency distribution of students by individual factors in Jimma Zone preparatory schools, February, 2012

\begin{tabular}{|c|c|c|}
\hline \multirow[t]{2}{*}{ VARIABLES } & \multicolumn{2}{|c|}{ SEX } \\
\hline & Male (\%) & Female $(\%)$ \\
\hline \multicolumn{3}{|l|}{ Have had sex in the last six months } \\
\hline Yes & $85(33.1 \%)$ & $116(44.6 \%)$ \\
\hline No & $172(66.9 \%)$ & $144(55.4 \%)$ \\
\hline \multicolumn{3}{|l|}{ Age of first sex } \\
\hline$<18$ & $23(27.1 \%)$ & $27(23.3 \%)$ \\
\hline $18-24$ & $62(72.9)$ & $89(76.7 \%)$ \\
\hline \multicolumn{3}{|l|}{ Religious attending } \\
\hline Yes & $76(29.6 \%)$ & $103(39.6 \%)$ \\
\hline No & $181(70.4 \%)$ & $157(60.4 \%)$ \\
\hline \multicolumn{3}{|l|}{ Frequency of Religious attending } \\
\hline Daily & $17(22.4 \%)$ & $23(22.1 \%)$ \\
\hline Most of the time & $24(31.6 \%)$ & $48(46.2 \%)$ \\
\hline Once per week & $12(15.8 \%)$ & $19(18.3 \%)$ \\
\hline Once per month & $13(17.1 \%)$ & $6(5.8 \%)$ \\
\hline Never visit & $10(13.2 \%)$ & $8(7.7 \%)$ \\
\hline \multicolumn{3}{|l|}{ Alcohol Consumption } \\
\hline Yes & $87(33.9 \%)$ & $72(27.7 \%)$ \\
\hline No & $170(66.1 \%)$ & $188(72.3 \%)$ \\
\hline \multicolumn{3}{|l|}{ Watch pornographic film } \\
\hline Yes & $115(44.7 \%)$ & $71(27.3 \%)$ \\
\hline No & $142(55.3 \%)$ & $189(72.7 \%)$ \\
\hline \multicolumn{3}{|l|}{ Chewing Khat } \\
\hline Yes & $116(45.1 \%)$ & $89(34.2 \%)$ \\
\hline No & $141(54.9 \%)$ & $171(65.8 \%)$ \\
\hline \multicolumn{3}{|l|}{ Number of sexual partners with in last 6} \\
\hline months $-[\mathrm{N}=$ Male $=85$, Female $=116)$ & $63(74.1 \%)$ & $91(78.4 \%)$ \\
\hline One & $22(25.9 \%)$ & $25(21.6 \%)$ \\
\hline \multicolumn{3}{|l|}{ Two or more } \\
\hline \multicolumn{3}{|l|}{ Consistent condom use $[\mathrm{N}=$ Male 85 , } \\
\hline Female $=116]$ & $8(9.4 \%)$ & $10(8.6 \%)$ \\
\hline Yes & $77(90.6 \%)$ & $106(91.4 \%)$ \\
\hline No & & \\
\hline \multicolumn{3}{|l|}{ Sexual Risk Behavior } \\
\hline At Risk & $83(32.3 \%)$ & $113(43.5 \%)$ \\
\hline Not At Risk & $174(67.7 \%)$ & $147(56.5 \%)$ \\
\hline Family connectedness* & $38.45(\mathrm{SD} \pm 11.0)$ & $36.57(\mathrm{SD} \pm 12.7)$ \\
\hline family support* & $28.69(\mathrm{SD} \pm 5.8)$ & $28.74(\mathrm{SD} \pm 5.3)$ \\
\hline School attachment* & $16.70(\mathrm{SD} \pm 3.0)$ & $16.62(\mathrm{SD}+3.0$ \\
\hline Community factors* & $22.00(\mathrm{SD}+5.6)$ & $21.38(\mathrm{SD}+5.1)$ \\
\hline
\end{tabular}

$*=i s$ continuous variables with their mean scores

Comparison of risky sexual behaviors among male and female students: The analysis showed that female students were 1.6 times more likely to be at risk than male students (OR $(95 \% \mathrm{CI}), 1.6$ [1.2-2.3, $\mathrm{P}<0.05$ ).

Independent predictors of female risky sexual behavior: Female students living away from their parents were three times more likely to be at risk than those living with their parents (OR 95\%CI 3.0(1.48-6.34)). Female students whose mothers were illiterate were 14 times more likely to be at risk than female students whose mothers' educational status was secondary school and above (OR, 95\%CI, 14.13(4.6-43)). Female students whose mothers 
could only read and write were 5 times more likely to be at risk than female students whose mothers educational status was secondary school and above (OR, 95\%CI, 5.44(1.7-17.0)).The likelihood of being at risk among female students who consumed alcohol was 7 times higher than those who did not consume alcohol (OR 95\%CI 7.27(3.3615.7)). For a unit increase in the total score of family connection with female students, the odds of becoming at risk was reduced by 0.93 (OR, 95\% CI, 0.93(0.89-0.96)) (Table 3).

Table 3: Multivariate Analysis of Risky Sexual Behaviors among Female Students in Jimma Zone Preparatory Schools, February, 2012

\begin{tabular}{|c|c|c|c|c|}
\hline \multirow[b]{2}{*}{ Variable } & \multicolumn{2}{|c|}{ RISKY SEXUAL BEHAVIOR } & \multirow[t]{2}{*}{$\mathrm{COR}(95 \% \mathrm{CI})$} & \multirow[b]{2}{*}{$\operatorname{AOR}[95 \% \mathrm{CI}]$} \\
\hline & $\begin{array}{l}\text { NOT AT RISK } \\
\text { oo }(\%)\end{array}$ & $\begin{array}{l}\text { AT RISK } \\
\text { № }(\%)\end{array}$ & & \\
\hline \multicolumn{5}{|l|}{ Living Arrangements } \\
\hline Living with parents & $45(34.9)$ & $84(65.1)$ & 0 . & $\mathbf{0}$ \\
\hline living away from parents & 102(77.9) & $29(22.1)$ & $0.15(0.09-0.26)^{*}$ & $3.0(1.48-6.34) *$ \\
\hline Residence & $47(37.0)$ & $80(63.0)$ & & \\
\hline Rural & $100(75.2)$ & $33(24.8)$ & 0 & $2.1(0.63-7.1)$ \\
\hline Urban & & & $0.19(0.11-0.33) *$ & \\
\hline \multicolumn{5}{|l|}{ Educational status of Mother } \\
\hline Illiterate & $36(34.6)$ & $68(65.4)$ & $0.24(0.13-0.44)^{*}$ & $14.13(4.6-43)^{*}$ \\
\hline Read and write & $62(68.9)$ & $28(31.1)$ & $0.25(0.10-0.63) *$ & $5.44(1.7-17.0) *$ \\
\hline Elementary & $17(68.0)$ & $8(32.0)$ & $0.15(0.06-0.35)^{*}$ & $4.5(1.02-20.0)$ \\
\hline Secondary and above & $32(78.0)$ & $9(22.0)$ & 0 & 0 \\
\hline \multicolumn{5}{|l|}{ Educational status of father } \\
\hline Illiterate & $25(39.7)$ & $38(60.3)$ & $0.54(0.27-1.05)$ & $0.55(0.16-1.90)$ \\
\hline Read and write & $43(55.1)$ & $35(44.9)$ & $0.28(0.13-0.62)^{*}$ & $0.7(0.23-2.14)$ \\
\hline Elementary & $37(69.8)$ & $16(30.2)$ & $0.38(0.19-0.77) *$ & $0.45(0.14-1.5)$ \\
\hline Secondary and above & $42(63.6)$ & $24(36.4)$ & 0 & 0 \\
\hline \multicolumn{5}{|l|}{ Religious visit } \\
\hline Yes & $67(65.0)$ & $36(35.0)$ & $0.56[0.34-0.93)^{*}$ & $1.69(0.81-3.52)$ \\
\hline No & $80(51.0)$ & $77(49.0)$ & 0 & \\
\hline \multicolumn{5}{|l|}{ Alcohol Consumption } \\
\hline Yes & $16(22.2)$ & $56(77.8)$ & $0.12(0.07-0.24) *$ & 7.27(3.36-15.7)* \\
\hline No & $131(69.7)$ & $57(30.3)$ & 0 & $\mathbf{0}$ \\
\hline Family connectedness $* *$ & 40.71 & 31.27 & $0.94(0.929-0.96) *$ & $0.93(0.89-.96)^{*}$ \\
\hline Family support $* *$ & 29.43 & 27.97 & $0.95(0.91-0.99) *$ & $1.01(0.90-1.2)$ \\
\hline School attachment** & 17.14 & 15.87 & $0.86(0.79-0.94) *$ & $1.1(0.96-1.26)$ \\
\hline
\end{tabular}

*p-value $<0.05 \quad * *$ continuous variables

Independent predictors of male risky sexual behavior: Students who consumed alcohol were 2.8 times more likely to be at risk than students who did not take alcohol (OR 95\% CI, 2.81(1.3-6.06)). Male students whose mothers educational status was illiterate were 8 times more likely to be at risk than male students whose mothers' educational status was secondary school and above (OR, 95\%CI, 8.2(2.15-31.09)). Male students whose mothers could only read and write were 4 times more likely to be at risk than male students whose mothers educational status was secondary school and above (OR, 95\%CI, 4.09(1.13-14.77)).

Male students with illiterate fathers were 3.4 times more likely to be at risk than male students whose fathers educational status was secondary school and above [OR, 95\%CI, 3.35]1.07-10.52]. Male students who chew khat were 4.6 times more likely to be at risk than those who did not chew chat (OR 95\%CI, 4.58(1.95-10.76). For a unit increase in total score of family connectedness with male students, the odds of becoming at risk was reduced by 0.94 (OR, 95\%CI 0.94(0.91-0.97) (Table 4). 
Table 3: Multivariate analysis of risky sexual behaviors among male students in Jimma Zone preparatory schools, February, 2012

\begin{tabular}{|c|c|c|c|c|}
\hline \multirow[b]{2}{*}{ Variable } & \multicolumn{2}{|c|}{ RISKY SEXUAL BEHAVIOR } & \multirow[t]{2}{*}{$\mathrm{AOR}[95 \% \mathrm{CI}]$} & \multirow[b]{2}{*}{$\mathrm{AOR}[95 \% \mathrm{CI}]$} \\
\hline & $\begin{array}{l}\text { Not at risk } \\
\text { Noo }(\%)\end{array}$ & $\begin{array}{l}\text { At risk } \\
\text { Noo }(\%)\end{array}$ & & \\
\hline \multicolumn{5}{|l|}{ Educational status of mother } \\
\hline Illiterate & $40(23.0)$ & $39(47.0)$ & 8.28(2.15-31.19)* & 8.18 $(2.15-31.09) *$ \\
\hline Read and write & $67(38.5)$ & $31(37.3)$ & $4.29(1.13-15.16)^{*}$ & 4.09(1.13-14.77]* \\
\hline Elementary & $25(14.4)$ & $4(4.80$ & $0.78(.165-3.74)^{*}$ & $\mathbf{0 . 7 8}(0.165-3.70)$ \\
\hline Secondary and above & $42(24.1)$ & $9(10.8)$ & 0 & $\mathbf{0}$ \\
\hline \multicolumn{5}{|l|}{ Educational status of father } \\
\hline Illiterate & $24(13.8)$ & $40(48.2)$ & 3.45(1.07-10.62)* & 3.35(1.07-10.52)* \\
\hline Read and write & $52(29.9)$ & $15(18.1)$ & $0.20(0.06-0.71)^{*}$ & $0.19(0.06-0.61)^{*}$ \\
\hline Elementary & $43(24.7)$ & $6(7.2)$ & $0.26(0.07-0.94) *$ & $0.24(0.07-0.90) *$ \\
\hline Secondary and above & $55(31.6)$ & $22(26.5)$ & 0 & $\mathbf{0}$ \\
\hline \multicolumn{5}{|l|}{ Alcohol Consumption } \\
\hline Yes & $45(25.9)$ & $42(50.6)$ & $2.94(1.69-5.08) *$ & 2.81(1.3-6.06)* \\
\hline No & $129(74.1)$ & $41(49.4)$ & 0 & $\mathbf{0}$ \\
\hline \multicolumn{5}{|l|}{ Watch pornographic film } \\
\hline Yes & $57(32.8)$ & $58(69.9)$ & $4.76(2.71-8.38)^{*}$ & $2.1(0.35-12.6)$ \\
\hline No & $117(67.2)$ & $25(30.1)$ & 0 & 0 \\
\hline \multicolumn{5}{|l|}{ Chewing Khat } \\
\hline Yes & $58(33.3)$ & $58(69.9)$ & 4.64(2.64-8.16)* & $4.58[1.95-10.76]^{*}$ \\
\hline No & $116(66.7)$ & $25(30.1)$ & 0 & $\mathbf{0}$ \\
\hline Family connectedness $* *$ & 40.75 & 33.63 & $0.94(0.92-.97) *$ & $0.94(0.91-0.97) *$ \\
\hline Family support $* *$ & 29.90 & 26.13 & $0.89(0.84-0.93)^{*}$ & $0.96(0.89-1.04)$ \\
\hline
\end{tabular}

$*$ p-value $<0.05 \quad * *$ continuous variables

\section{DISCUSSION}

This study provides an insight into the operation of risk and protective factors in different dimension to predict risky sexual behavior among male and female preparatory school students in Jimma Zone. Thirty-three\% of the male and $44.6 \%$ of the female students had sex in the last six months. This result is very high when compared with the study conducted in other parts of Ethiopia (25) but low in comparison with the study conducted in Burkina Faso (26).This difference might be the result of cultural differences, availability of risk factors and community norms.

Thirty-four percent of the male and $27.7 \%$ of the female students consumed alcohol, $45 \%$ of the male and $27.3 \%$ of the female students watched pornographic movies in the last six months. This finding is higher than the findings of studies conducted in north Ethiopia, Burkina Faso and Kenya $(26,27,28,29)$. The possible reason might be differences in socio-cultural, availability of alcohol, the demographic characteristics of the study participants and the sample size. Forty-five percent of the male and $34.2 \%$ of the female students were chewing khat. This finding is very low in comparison with that of a study conducted in El Salvador (30). The possible reason might be the availability of khat, the demographic characteristics of the study participants and the sample size.

Twenty-six percent of the male and $21.6 \%$ of the female students had two or more sexual partners in the last six months. The result of the males is similar to the study conducted in Kenya and that of the females is very low when compared with the result of a study conducted in Kenya (31). The possible reason might be the community norm about multiple sexual partners and the level of HIV/AIDS awareness difference in the two countries.

Thirty-two percent of the male and $43.5 \%$ of the female students were sexually at risk in the last six months. This finding is very high when compared with a study conducted in Ethiopia (25). This difference might be distinctions in the sociodemographic characteristics of the study participants 
and cultural difference between the two study areas. Only $9.4 \%$ of the male and $8.6 \%$ of the female students used condom consistently in the last six months. This finding is lower than the finding of a study conducted in Kenya (28). This might be due to low risk perception among students and community norms regarding condom use.

Female students were 1.6 times more likely to be at risk than male students. Due to socio-cultural reasons, females are more susceptible to sexual risks. This finding is similarly to the studies conducted in Nigeria and Dessie Preparatory School, Ethiopia (18, 20).

Alcohol consumption was a significant predictor of risky sexual behavior for both female and male students. Many studies also indicated that alcohol users were more likely to have non-regular sex partner than non-khat users $(32,9,33)$. Adolescents were more likely to engage in risky sexual practices such as having multiple sex partners, exercising unprotected sexual intercourse, and selecting higher risk partners after drinking alcohols $(7,11)$.

When we see family connectedness, it remained significantly associated with risky sexual behavior among both groups of students (males and females) as a protective factor. Several studies found out that positive relationships, i.e. connectedness between parents and adolescents is linked to avoidance or lower use of alcohol, tobacco, and drugs and is less likely to initiate sex or sexual activity. On the contrary, poor-quality parent-youth relationships were associated with increased sexual activity $(34,35,36)$.

Female students who were living way from their parents were three times more likely to be at risk than those who were living with their parents. This finding is similar to studies conducted in many countries $(8,34,35,36)$. Numerous studies recommended family interventions to improve parent-child communication, supportive parenting, and parental monitoring.

Female students whose mothers were illiterate were more at sexual risk than students whose mothers' education status was secondary school and above. For male students, the educational status of both their mothers and fathers remained significantly associated with risky sexual behavior. Male students whose mothers and fathers were illiterate were more likely to be at sexual risk than male students from parents with secondary education and above. This finding is similar with the findings of studies conducted in Ethiopia and Salvadoran $(30,37)$. Thus, parental education is also an important factor for understanding engagement in risky behavior among youths.

Male students who chewed khat were more likely to be at risk than those who did not chew khat. This finding is similar with the findings of studies conducted in Ethiopia, Kenya and South Africa. (38). These studies concluded that daily khat intake followed by alcohol consumption was associated with unprotected sex which puts adolescents at the highest risk in terms of sexual behavior.

From this study, we can conclude that large proportions of male and female students were sexually active in the last six months. But, very few of them used condom consistently. Living arrangement, educational status of parents, family connectedness, alcohol consumption and chewing khat were the major predictors of risky sexual behaviors among male and female students. Therefore, schools, families and zonal education office should be involved in reducing the risky sexual behavior of school youth. Improving parent-youth connectedness and family support should be the primary focus for interventions because familyfocused interventions have a positive effect on students' behaviors.

\section{ACKNOWLEDGMENTS}

We would like to extend our thanks to the Department of Health Education and Behavioral Sciences, College of Public Health and Medical Sciences, Jimma University, for its financial and technical supports. We also convey our special thanks to Zonal Health Office, Zonal Education Department, data collectors, supervisors and study participants.

\section{REFERENCES}

1. EPHA, ARH. Task force Adolescent Reproductive Health Global and National initiatives: Lesson Learned, Aug .2003.

2. Blum R. School connectedness: Improving students lives. John Hopkins Bloomberg School of Public Health. Baltimore, 2005.

3. Family Health international youth Net program. Intervention strategies that work for youth summary of Focus on youth adults. Youth issues, 2002; purer 1 . 
4. WHO. Report on the Global AIDS epidemic. World Health Organization, 2009.

5. Dawud A. Perception of the risks of sexual activities among out-of school adolescents in South Gondar Administrative Zone. Amhara Region, 2003.

6. Govindasamy P, Kidanu A. Youth reproductive health in Ethiopia. OCR Macro, 2002; POPLINE Document Number: 183584.

7. Cooper M. Lynne. Alcohol use and risky sexual behavior among college students and youth: Evaluating the evidence. Journal of Studies on Alcohol, 2002; 14(14): 101-117.

8. Prinstein Mitchell J, Annette M. La Greca. Childhood peer rejection and aggression as predictors of adolescent girls' externalizing and health risk behaviors: a 6-year longitudinal study. Journal of Consulting and Clinical Psychology, 2004; 72(1): 103-112.

9. Russell TV, Do AN, Setik E, Sullivan PS, Rayle VD, et al. Sexual Risk Behaviors for HIV/AIDS in Chuuk State, Micronesia: The Case for HIV Prevention in Vulnerable Remote Populations. PLOS ONE 2007, 2(12): e1283.

10. Hargreaves J, Morison L, Bonell C, Porter J. The association between school attendance, HIV infection and sexual behaviour among young people in rural South Africa. J Epidemiology Community Health, 2008; 62(2), 113-119.

11. Policy brief: Protecting in-School Adolescents from HIV/ AIDS, STIs and Unwanted Pregnancy: Evidence-based Lessons for Programs and Policy. Policy Brief, 2009; No.11.

12. FMOH. International strategies that work for youth; summary of focus on young adults: End of program report. Ethiopia, 2002.

13. Ed Scholl, Jane Schueller, Mulugeta Gashaw, Abiye Wagaw, Liya Wolde Michael. Assessment of Youth Reproductive Health Programs in Ethiopia. FHI for Youth Net, 2004: No. GPH-A-00-01-00013-00.

14. CSA E, International I. Ethiopia Demographic and Health Survey 2011. Addis Ababa, Ethiopia and Calverton, Maryland, USA, 2012.

15. Jimma zone and Jimma town Education Offices, 2011.

16. Lemma E. Predictors of HIV/AIDS related sexual behavior of high-school adolescents, Jimma town, southwest Ethiopia, 2000.

17. Tadesse E, Gudunfa A. and Mengistu G. Survey of adolescent reproductive health in the city of Addis Ababa. Ethiop.J.Health dev., 1996; 10(1):35-39.
18. Gail B Slap, Lucy Lot, Bin Huang. Sexual behavior of adolescents in Nigeria among secondary school students. BMJ, 2003; Vol 326(4): 15-18.

19. Eaton DK, Kann L, Kinchen S, Shanklin S. Youth risk behavior surveillance in United States: Morbidity and mortality weekly report. MMWR Surveill Summ. 2008; 57(4):1-131.

20. Shiferaw S. The Effect of Living Arrangements and Parental Attachment on Sexual Risk behaviors and Psychosocial Problems of Adolescents in Dessie Preparatory School in Ethiopia , 2004.

21. Astrat A. Assessment of sexual risk behaviors of in-school youth: effect of living arrangement of students, West Gojjam Zone, Amhara regional state, Ethiopia , 2009.

22. Yi S, Poudel KC, Yasuoka J, Palmer PH, Yi S, Jimba M. Role of risk and protective factors in risky sexual behavior among high school students in Cambodia. BMC public health, 2010; 10(1): 477.

23. Le TN, Kato T. The role of peer and culture in risky sexual behavior for Cambodian and Lao/Mien adolescents. J Adolescent Health, 2006; 38:288-296.

24. Hu G, Sun Z, Hu M, Xia Q, Yin X, Zheng L, Castillo RC. Brief report Development of a brief scale to assess family support function among Chinese high school students. J Adolescent, 2007; 30:879-879.

25. DKT Ethiopia and FHAPCO. Study of Condom use and behavior among venue-based sex workers and their clients in major urban areas of Ethiopia, 2009.

26. Khan M, Brown L. HIV-related sexual behavior in urban, rural and border areas of Burkina Faso. AIDS and Behavior, 2006; 10(5): 607-617.

27. Westercamp N, Moses S. Research spatial distribution and cluster analysis of sexual risk behaviors reported by young men in Kisumu, Kenya, 2011.

28. Mazengia F. and Worku A. Age at sexual initiation and factors associated with it among youths in North East Ethiopia. Ethiopian Journal of Health Development, 2006; 23(2).

29. Voeten H, Egesah B. Sexual behavior is more risky in rural than in urban areas among young women in Nyanza province, Kenya. Sexually transmitted diseases, 2004; 31(8): 481.

30. Springer A. Perceived parental monitoring and health risk behavior among public secondary 
school students in El Salvador. Scientific World Journal, 2006; 28(6): 1810-4.

31. Akwara P, Madise J. Perception of risk of HIV/AIDS and sexual behaviour in Kenya. Journal of Biosocial Science, 2003; 35(3): 385411.

32. Kliewer W, Murrelle L. Risk and protective factors for adolescent substance use: Findings from a study in selected Central American countries. J Adolesc Health 2007, 40:448-455.

33. Malhotra, S. Impact of the Sexual Revolution: Consequences of Risky Sexual Behaviors. Journal of American Physicians and Surgeons, 2008; 13(3): 88.

34. Astatke H, Black M, Serpell R. Use of Jessor's theoretical framework of adolescent risk behavior in Ethiopia: implications for HIV/
AIDS prevention. Northeast African Studies, 2000; 7(1): 63-83.

35. Moore K. Child Trends. Parent-youths relationships and interactions: Far more positive than not, Child Trends, 2004.

36. Boyar R, Levine D, Zensius N. Youth Sexuality and Reproductive Health in the Digital Age. Oakland, CA: ISIS, Inc. April, 2011.

37. Seme A, Wirtu D. Premarital sexual practice among school adolescents in Nekemtie Town, East Wollega. Ethiopian Journal of Health Development, 2009; 22(2): 167-173.

38. Brook JS, Morojele, NK, Pahl T, Brook.D. Predictors of drug use among South African Adolescents. Journal of Adolescent Health, 2006; 38(1): 26-34. 